\title{
O DELITO DE LAVAGEM DE CAPITAIS E A TEORIA DA CEGUEIRA DELIBERADA: COMPATIBILIDADE NO DIREITO PENAL BRASILEIRO?
}

\author{
Sebastian Borges de Albuquerque Mello ${ }^{1}$ \\ Camila Ribeiro Hernandes ${ }^{2}$
}

Resumo: O presente trabalho objetiva discutir a possibilidade de aplicação da teoria da cegueira deliberada no delito de lavagem de capitais. É bastante controvertida a delimitação do elemento subjetivo no delito de lavagem de capitais, sobretudo no que tange à admissibilidade do dolo eventual. Nessa linha, discute-se a possibilidade de inclusão ou adaptação da cegueira deliberada (willful blindness) no direito brasileiro, seja como uma forma equiparada ao dolo eventual, seja como um elemento subjetivo próprio e autônomo.

Palavras-chave: Lavagem de capitais. Dolo eventual. Cegueira deliberada. Elemento subjetivo. Compatibilidade.

\section{MONEY LAUDERING CRIME AND WILLFUL BLINDNESS DOCTRINE: COMPATIBILITY IN BRAZILIAN CRIMINAL LAW?}

\begin{abstract}
The present article proposes to discuss the possibility to use the willful blindness theory in the money laundering delict. It is quite controversial the subjective element's limitation in the money laundering delict, mostly in what concerns the admissibility of the eventual intention (dolus eventualis). In that line, the possibility of inclusion or adaptation of the willful blindness is under discussion in the brazilian law, either as an assimilated form of the eventual intention (dolus eventualis) or as an independent and personal subjective element.
\end{abstract}

Keywords: Money laundering. Eventual intention. Willful blindness. Subjective element. Compatibility.

\footnotetext{
${ }^{1}$ Mestre e doutor em Direito pela UFBA. Professor Adjunto da Graduação, mestrado e doutorado da UFBA e professor da Faculdade Baiana de Direito. Membro do Instituto Baiano de Direito Processual Penal Salvador/BA. Advogado. E-mail: sbam@terra.com.br

${ }^{2}$ Mestranda em Direito Público pela UFBA. Especialista em Ciências Criminais pela Universidade Católica do Salvador. Membro do Instituto Baiano de Direito Processual Penal - Salvador/BA. Advogada. E-mail: camilarhernandes@gmail.com
} 


\section{INTRODUÇÃO}

O elemento subjetivo no delito de lavagem de capitais tem sido um dos temas mais tormentosos a ser enfrentado pela doutrina e pela jurisprudência, e traz à baila a questão, nem sempre bem delimitada, sobre as distinções entre dolo e culpa no direito brasileiro. É certo que as construções doutrinárias tradicionais sobre dolo ainda remontam às teorias da vontade, representação e assentimento, cujas origens remontam ao século XIX. Quem acompanha a questão mais de perto, contudo, tem percebido abordagens contemporâneas que caminham para uma certa "objetivação" do conceito de dolo, estabelecendo uma aparente "normativização" daquilo que tradicionalmente se chama de "conhecimento" e "vontade".

O fato é que, em delitos como o de lavagem de dinheiro, existem sensíveis dificuldades na determinação e prova do elemento subjetivo num caso concreto, devendo-se perguntar se as estruturas de imputação subjetiva devem permanecer intactas ou devem ser reposicionadas para adaptar-se à nova realidade.

Pode-se, de um lado, recorrer à tentação de se manter inalterados os critérios tradicionais de dolo e culpa, aplicando-se, sem muitas variações, uma hermenêutica ortodoxa do artigo 18 do Código Penal, atendendo aos postulados de legalidade e segurança jurídica. De outro, em linha diametralmente oposta, pode-se recorrer a critérios que, malgrado possuam nomenclaturas distintas, podem representar hipóteses de responsabilidade penal solidária e objetiva.

Desta maneira é que surge, como critério interpretativo do elemento subjetivo, a doutrina da cegueira deliberada, tradução da willful blindness do common law, também chamada de doutrina das instruções do avestruz (ostrich instructions), ignorancia deliberada ou mesmo doutrina da evitação da consciência (conscious avoidance doctrine).

A willful blindness tem sido utilizada pelos tribunais norte-americanos para admitir a imputação subjetiva no tipo penal de lavagem de capitais, notadamente nos casos em que o agente tinha consciência da elevada probabilidade de que os bens ou recursos envolvidos eram provenientes de infração antecedente e, ainda assim, agiu de modo indiferente a esse conhecimento.

No Brasil, a referida doutrina tem sido utilizada amiúde como sucedâneo do dolo eventual, sobretudo como forma de compatibilizar dito instituto com o elemento subjetivo do crime de lavagem de capitais. Em nome de um discurso utilitarista, tem-se admitido a aplicação da teoria da cegueira deliberada para a imputação de responsabilidade penal subjetiva, a pretexto de tornar mais eficiente a persecução penal do crime de reciclagem de ativos. Neste 
contexto, o presente artigo objetiva examinar a origem e o conteúdo da doutrina da cegueira deliberada e a viabilidade, ou não, de sua aplicação ao delito de lavagem de capitais tal como previsto na legislação brasileira.

A primeira parte do texto dedica-se, então, a uma visão global do delito de lavagem de capitais, notadamente no que se refere aos tipos penais previstos na Lei n. 9.613/1998 e a discussão existente em torno do elemento subjetivo do crime, ponto fulcral do presente estudo. No segundo momento da pesquisa, abordaremos a teoria da cegueira deliberada, apresentando seus aspectos gerais e as principais dificuldades apontadas para a sua aplicação, para então adentrar especificamente na problemática referente à compatibilidade, ou não, entre o instituto e a infração penal de reciclagem de ativos.

\section{O DELITO DE LAVAGEM DE CAPITAIS NA LEI N. 9.613/1998}

O Brasil assumiu o compromisso jurídico internacional de criminalizar a lavagem de dinheiro quando assinou a Convenção de Viena, incorporada ao direito interno através do Decreto n. 154/1991. Nada obstante, a Lei n. 9.613, que tipifica o delito no país, apenas foi sancionada em 3 de março de 1998, sofrendo modificações em 2002 (Lei n. 10.467) e em 2003 (Lei n. 10.701). Por fim, em 2012, a Lei n. 12.683 introduziu profundas alterações no texto em vigor, dentre as quais destacamos a eliminação do rol de crimes antecedentes.

A expressão lavagem de capitais corresponde ao conjunto de operações que tem por objetivo conferir aparência de licitude a bens, recursos e valores provenientes de uma infração penal, com a sua consequente reinserção no sistema econômico-financeiro. De forma objetiva, Nuno Brandão (2002, p. 15, tradução nossa) indica que "O branqueamento ${ }^{3}$ de capitais é a atividade pela qual se procura dissimular a origem criminosa de bens ou produtos, procurando dar-lhes uma aparência legal”. Ou, conforme lição de Fabián Caparrós (1998, p. 76), o processo tendente a conferir progressiva aparência de legalidade a uma massa patrimonial derivada de condutas ilícitas, objetivando sua posterior aplicação em atividades econômicas regulares.

\footnotetext{
${ }^{3}$ Nações como a França, Bélgica, Espanha e Portugal adotam como núcleo da denominação do crime a palavra "branqueamento". No Brasil, O Ministério da Justiça fundamentou a opção legislativa pelo vocábulo "lavagem" em duas razões, expressamente destacadas na exposição de motivos da Lei n. 9.613/1998, segundo a qual "A expressão 'lavagem de dinheiro' já está consagrada no glossário das atividades financeiras e na linguagem popular, em consequência de seu emprego internacional (money laudering). Por outro lado, conforme o Ministro da Justiça teve oportunidade de sustentar em reunião ocorrida em Maputo (Moçambique), a denominação 'branqueamento', além de não estar inserida no contexto da linguagem formal ou coloquial em nosso País, sugere a inferência racista do vocábulo, motivando estéreis e inoportunas discussões."
} 
Por todo o exposto, infere-se que a lavagem de dinheiro é o conjunto de ações pelas quais se busca ocultar a existência, a fonte ilegítima ou a aplicação ilegal de renda, convertendo o produto originário de uma atividade criminosa em fundos de procedência aparentemente lícita. Revela-se como um fenômeno socioeconômico antigo, sendo imperioso, para os fins do presente trabalho, adentrar ao estudo, embora sucinto, dos tipos penais previstos na Lei n. 9.613/1998 e da tormentosa questão relativa ao elemento subjetivo do crime.

\subsection{TIPOS PENAIS}

A Lei n. 9.613/1998 incrimina as condutas relacionadas com o processo de lavagem em seu artigo $1^{\circ}$, apresentando quatro comportamentos típicos distintos: a) ocultação ou dissimulação de bens, direitos ou valores provenientes de infração penal (caput); b) uso de meios para ocultação ou dissimulação dos proveitos de origem ilícita ( $\$ 1^{\circ}$, incisos I a III); c) utilização de recursos advindos de fonte criminosa na atividade econômica ou financeira $\left(\S 2^{\circ}\right.$, inciso I); e d) participação em entidade destinada à lavagem de capitais ( $§ 2^{\circ}$, inciso II).

Pelo que se pode inferir da própria disposição de cada uma das modalidades de reciclagem de ativos na legislação brasileira, decerto que a conduta básica que concretiza o delito em exame é aquela prevista no caput do citado dispositivo, consistente em ocultar ou dissimular a natureza, origem, localização, disposição, movimentação ou propriedade dos capitais oriundos, direta ou indiretamente, de uma infração penal anterior. Trata-se, pois, da criminalização da primeira e da segunda fases do processo de lavagem. ${ }^{4}$

O tipo objetivo do artigo $1^{\circ}$, caput, portanto, exige algum ato de mascaramento do valor procedente da infração penal anterior, não se confundindo com o mero aproveitamento do produto do crime. Noutros termos, o tão somente ato de usufruir dos recursos advindos da conduta delitiva, propósito natural daquele que se aventura a praticar um ilícito com resultado patrimonial, por não ofender diretamente a ordem econômica, não configura a lavagem.

Ademais, todos os tipos da Lei n. 9.613/1998 são delitos acessórios, porquanto não haverá reciclagem de ativos se não ocorrer uma infração em momento anterior que gere bens ou valores aptos a serem "lavados" (DE CARLI, 2011, p. 183). O crime ou contravenção

\footnotetext{
${ }^{4}$ A doutrina procura agrupar os atos que compõem o processo de lavagem em três fases. Assim, como resumem Gustavo Badaró e Pierpaolo Bottini (2012, p. 23, grifos no original), a operação se inicia com a ocultação dos valores ilicitamente auferidos, desenvolve-se nas operações posteriores para a dissimulação da origem dos bens, e se conclui pela reinserção do capital já lavado na economia formal ou no sistema financeiro.
} 
precedente, pois, é elemento normativo de todas as modalidades de lavagem de dinheiro previstas na legislação própria, aí encontrando justificativa a exigência de que a denúncia seja instruída com indícios suficientes de sua existência (artigo $2^{\circ}, \S 1^{\circ}$, da Lei n. 9.613/1998).

Passando para a análise das figuras equiparadas à do caput, observa-se que os delitos elencados no $\S 1^{\circ}$ do multicitado artigo $1^{\circ}$ da lei exigem a comprovação do dolo específico do agente de ocultar ou dissimular a utilização dos bens, direitos ou valores provenientes da infração penal precedente. Dirigem-se, então, aos partícipes da conduta principal, sendo que, em todos os casos, é exigida a demonstração da consciência sobre a origem criminosa dos bens para que o tipo penal reste caracterizado.

Dito isso, comete lavagem de dinheiro aquele que concorre para a ocultação ou dissimulação valendo-se, com esse propósito, de meios destinados a alterar a natureza ilícita dos valores envolvidos. Tal prática pode ocorrer com a conversão dos ditos valores em recursos lícitos (inciso I), com a aquisição ou com a negociação desses ativos (inciso II), ou, ainda, com o superfaturamento de importações ou exportações (inciso III).

$\mathrm{O} \S 2^{\circ}$ do artigo, por sua vez, traz outras duas formas derivadas do crime de lavagem de dinheiro, incriminando a atuação de quem utiliza, na atividade econômica ou financeira, recursos de origem ilícita (inciso I), bem como do agente que participa de entidade tendo conhecimento de que sua atividade principal ou secundária é dirigida à prática daquele delito (inciso II). ${ }^{5}$

\subsection{A QUESTÃO DO ELEMENTO SUBJETIVO}

Sabe-se que na redação original da Lei n. 9.613/1998, bem como nas sucessivas mudanças legislativas subsequentes, não houve qualquer consideração especial do legislador no que se refere ao elemento subjetivo do tipo de lavagem de dinheiro. Certo é que, não havendo previsão expressa da modalidade culposa, o delito somente pode ser praticado a título de dolo, haja vista a excepcionalidade do crime culposo no ordenamento pátrio.

A previsão exclusiva da forma dolosa representa, na visão de Gustavo Badaró e Pierpaolo Bottini (2012, p. 93), uma importante garantia de imputação subjetiva, afastando a possibilidade de responsabilização objetiva na seara penal ao exigir, na ótica dos referidos

\footnotetext{
${ }^{5}$ Tigre Maia (1999, p. 102) chama a atenção para a redação mal elaborada do tipo, o qual faz uso dos vocábulos grupo e escritório, que "não concedem ao aplicador da lei qualquer parâmetro objetivo para fixar o quantitativo mínimo de agentes necessários (e.g., duas ou mais pessoas etc.) à prática do ilícito associativo.”
} 
autores, a demonstração de uma relação psíquica com os fatos, englobando o conhecimento dos elementos típicos e a vontade de executar ou colaborar com sua realização.

Malgrado tratar-se de garantia inegável, a mera previsão da forma dolosa não resolve, contudo, uma série de questões pendentes, desde a existência ou não de algum elemento subjetivo especial do tipo, bem como as questões relativas ao dolo eventual e a assunção do risco nos delitos de lavagem de capitais. Dentro desse contexto, forçoso concluir que a pesquisa do elemento subjetivo na conduta de ocultar ou dissimular o produto resultante de anterior infração penal, a fim conferir-lhe aparência lícita e promover sua reintegração à economia formal, é de suma importância para a caracterização do crime de lavagem de capitais.

Num viés que interpreta o elemento subjetivo de maneira mais extensiva e utilitarista, Sergio Moro (2007, p. 95) destaca que, nada obstante o dolo no crime de lavagem abarque a consciência da infração penal antecedente, exigir do sujeito ativo preciso conhecimento acerca de suas circunstâncias e elementos teria significativo impacto na eficácia da lei, notadamente em virtude da "terceirização" do delito, que tem como consequência certo distanciamento entre o seu agente e o agente da conduta que produziu os ativos a serem reciclados.

Para essa linha de pensamento, exige-se apenas que o indivíduo detenha conhecimento de que o objeto da reciclagem constitui produto de alguma infração penal, mas não que ele saiba, de forma detalhada, a espécie de atividade criminosa, máxime quando se tem em mente que a Lei n. 12.683/2012 eliminou o rol taxativo anteriormente previsto no artigo $1^{\circ}$, permitindo que qualquer crime ou contravenção produtor de ativos seja antecedente ao mascaramento.

A prova do elemento subjetivo, tarefa penosa para a acusação, reveste-se de dificuldade ainda maior face à complexidade do crime de lavagem de capitais. Diante dessa realidade, é comum a referência em documentos internacionais à possibilidade de comprovação do dolo por elementos objetivos, como no artigo $6^{\circ}, \S 2^{\circ}$, f, da Convenção de Palermo. ${ }^{6}$

O entendimento conferido às normas em questão mereceu atenção da doutrina, a qual esclarece que a objetividade da prova do dolo "não deve ser interpretada no sentido de que pode ser dispensada a prova do elemento subjetivo, reduzindo a carga imposta à acusação e impondo alguma espécie de responsabilidade objetiva pelo crime de lavagem”. (MORO, 2007, p. 103).

Admitir que a comprovação do dolo seja feita a partir de circunstâncias objetivas não significa substituí-lo por elementos objetivos, transformando-o em um conceito carente de

\footnotetext{
6 Segundo o dispositivo em questão: “O conhecimento, a intenção ou a motivação, enquanto elementos constitutivos de uma infração enunciada no parágrafo 1 do presente Artigo, poderão inferir-se de circunstâncias fatuais objetivas".
} 
qualquer conteúdo psicológico (BADARÓ; BOTTINI, 2012, p. 93-94). O direito penal pressupõe a responsabilidade somente por fatos que decorram da vontade do indivíduo, sem o qual não se poderá falar em tipicidade.

Questão tormentosa e imprescindível a essa pesquisa, por fim, diz respeito ao cabimento, ou não, do dolo eventual.

Dolo, na previsão expressa no Código Penal, é a consciência e a vontade dirigida à prática da conduta típica, bem como a vontade que, embora não diretamente voltada ao resultado previsto como provável, consente no advento desse ou assume o risco de produzi-lo (artigo 18, I, do Código Penal). Na hipótese específica do delito em estudo, portanto, seria a consciência de que os bens direitos ou valores tem origem criminosa e a vontade de ocultar ou dissimular sua natureza, origem, localização disposição movimentação ou propriedade.

Sem olvidar das próprias peculiaridades que envolvem o conceito de dolo na atualidade $^{7}$, há sérias controvérsias sobre a admissibilidade do dolo eventual no crime de lavagem de dinheiro. Beck (2011, p. 58) considera que os delitos dolosos admitem as formas dolosas direta e eventual, exceto naqueles casos em que o próprio tipo usa expressões típicas do dolo direto. Logo, conclui que, nos termos da teoria geral do delito, não é possível a exclusão apriorística do dolo eventual no delito de lavagem de capitais.

Contudo, alguns delitos previstos na Lei n. 9.613/1998, em razão da redação dos respectivos tipos, não se compatibilizam com o dolo eventual. $\mathrm{O}$ artigo $1^{\mathrm{o}}, \S 1^{\mathrm{o} 8}$, estabelece que a punição do infrator resta condicionada à existência de um especial fim de agir, sem o qual não se perfectibiliza o delito de lavagem. Por outro lado, a norma legal incriminadora prevista no artigo $1^{\circ}, \S 2^{\circ}, \mathrm{II}^{9}$, exige um elemento subjetivo do tipo, qual seja, a comprovação de que o sujeito tem conhecimento de que a atividade principal ou secundária do grupo a que pertence está dirigida à prática do mascaramento de capitais (MELLO, 1999, p.38).

Antes das alterações introduzidas no referido diploma legal, unânime era o entendimento acima também no que se refere ao tipo previsto no inciso I do $\S 2^{\circ}$, haja vista que

\footnotetext{
${ }^{7}$ Há significativa corrente de pensamento contemporâneo que considera que o dolo e a imprudência seriam conceitos normativos a serem determinados pela ciência dogmática e pela jurisprudência, conforme pensamento de autores como Feijoo (1998, p. 271), Greco (2009, p. 902) e Porciúncula (2014, p. 37).

$8 \S 1^{\text {o }}$ Incorre na mesma pena quem, para ocultar ou dissimular a utilização de bens, direitos ou valores provenientes de infração penal: [...] (grifos nossos).

${ }^{9} \S 2^{\circ}$ Incorre, ainda, na mesma pena quem: (...) II - participa de grupo, associação ou escritório tendo conhecimento de que sua atividade principal ou secundária é dirigida à prática de crimes previstos nesta lei.
} 
sua redação original, textualmente, exigia a ciência da origem espúria dos ativos ${ }^{10}$. Com a supressão da expressão "que sabe", entretanto, surgiu o questionamento na doutrina sobre se teria sido substituído o dolo direito pelo dolo eventual, autorizando a punição mesmo em casos nos quais o agente não tem ciência plena de que os bens que recebe tem procedência infracional.

Ademais, quanto ao tipo básico do caput do artigo $1^{\circ}$ a discussão remonta ao próprio surgimento da lei. Entre os adeptos do dolo eventual para a configuração do delito, recorrente é a referência ao item 40 da Exposição de Motivos da Lei n. 9.613/1998, que deixa evidente a intenção do legislador sobre a questão:

\begin{abstract}
40. Equipara o projeto, ainda, ao crime de lavagem de dinheiro a importação ou exportação de bens com valores inexatos (art. $1^{\circ}, \S 1^{\circ}$, III). Nesta hipótese, como nas anteriores, exige o projeto que a conduta descrita tenha como objetivo a ocultação ou a dissimulação da utilização de bens, direitos ou valores oriundos dos referidos crimes antecedentes. Exige o projeto, nesses casos, o dolo direto, admitindo o dolo eventual somente para a hipótese do caput do artigo. (MINISTÉRIO DA JUSTIÇA, 1996, grifos nossos).
\end{abstract}

Sobre o tema, Rodrigo Leite Prado (2011, p. 230) pondera que a limitação da prática delitiva às hipóteses de dolo direto "reduziria à inutilidade boa parte do arcabouço normativo do qual é produto a Lei brasileira", cujo principal intuito seria o de reprimir a lavagem terceirizada, posto que "o profissional da lavagem dificilmente tem notícia da proveniência do objeto material do delito". Noutro viés, aponta que a regra em nosso ordenamento é a equiparação do dolo direto ao dolo eventual - assim, mesmo na ausência de menção direta a esta última modalidade no caput do artigo $1^{\circ}$, haveria a possibilidade de admiti-la diante da previsão geral contida no artigo 18, I, do Código Penal.

Em sentido oposto, há quem sustente que apenas pratica lavagem de dinheiro aquele que atua com dolo direto, possuindo plena ciência de que o produto tem origem delitiva e, a partir desse dado, agindo de forma livre e consciente com o propósito de promover sua ocultação ou dissimulação. Nessa linha, a Convenção de Viena ( $\operatorname{artigo} 3^{\circ}, \S 1^{\circ}$, b) e a Convenção de Palermo (artigo $6^{\circ}, \S 1^{\circ}$ ) indicam que apenas quem tem conhecimento da proveniência dos bens pode ser enquadrado no delito.

Para Barros (2012, p. 63-64) seria demasiadamente prejudicial ao sujeito acusado de lavagem eventual interpretação extensiva que, na ausência de previsão legal da forma culposa para o crime, admita sua substituição pela aplicação da teoria do dolo eventual. Nessa senda,

\footnotetext{
${ }^{10}$ Dizia o texto anterior à Lei n. 12.683/2012: $\S 2^{\circ}$ Incorre, ainda, na mesma pena quem: I - utiliza, na atividade econômica ou financeira, bens, direitos ou valores que sabe serem provenientes de qualquer dos crimes antecedentes referidos neste artigo. (grifos nossos).
} 
sem a demonstração da ciência prévia do agente sobre a origem ilícita dos valores, restará caracterizada a situação de erro de tipo quanto ao delito de lavagem, excluindo o dolo.

Na mesma linha, Badaró e Bottini (2012, p. 95-96) salientam que, malgrado a Exposição de Motivos da lei original contemple expressamente o cabimento do dolo eventual nas hipóteses do caput do artigo $1^{\circ}$, deve-se apreender o sentido da norma por meio de uma interpretação sistemática. Desse modo, acaso pretendesse o legislador, de fato, considerar possível a incidência do dolo eventual, teria evidenciado sua opção por meio da utilização da expressão "deve saber", tal como fez na redação de outros tipos penais que pressupõem o conhecimento de uma circunstância anterior ${ }^{11}$.

A jurisprudência pátria sobre o tema ainda é incipiente. Outrossim, no paradigmático julgamento da Ação Penal 470 (AP-470), conhecido como caso do "Mensalão", algumas incursões foram feitas acerca da matéria, sendo importante abordá-las sucintamente.

Na exposição de seu voto, a Ministra Rosa Weber asseverou não ser necessário qualquer elemento subjetivo especial para reconhecer-se o dolo eventual na lavagem de dinheiro, uma vez que isso decorreria da já citada previsão genérica do artigo 18, inciso I, do Código Penal, bem assim encontraria respaldo no item 40 da Exposição de Motivos 692/1996. Ainda, ponderou que não admitir a tipificação do crime com tal modalidade de dolo implicaria na impunidade, por exemplo, da terceirização da lavagem, eis que o profissional do delito, contratado pelo autor do crime antecedente para realizá-lo, adotaria, em geral, postura indiferente em relação à procedência criminosa dos bens envolvidos, e não raramente se recusaria a aprofundar o reconhecimento a respeito.

Seguindo semelhante orientação, o Ministro Celso de Mello admitiu a possibilidade de configuração do crime de lavagem de valores, mediante dolo eventual, com apoio na teoria da cegueira deliberada.

Em sentido oposto, o Ministro Marco Aurélio Mello manifestou preocupação com a interpretação dada ao tipo penal, afirmando que o assusta defender que, no caso da lavagem de dinheiro, contenta-se a ordem jurídica com o dolo eventual. Na visão do julgador, o delito de mascaramento apenas se compatibiliza com o dolo direto, exigindo a comprovação de que o acusado agiu com a intenção de dissimular a origem infracional dos recursos e reinseri-los na vida cotidiana com a aparência lícita.

\footnotetext{
${ }^{11}$ Como exemplo, mencionam os autores o crime de perigo de contágio venéreo (artigo 130 do Código Penal).
} 
No cipoal de entendimentos divergentes e conflitantes sobre o elemento subjetivo no crime de lavagem de dinheiro, passou-se a invocar a doutrina da cegueira deliberada como possível fundamento para a imputação subjetiva do delito.

\section{A TEORIA DA CEGUEIRA DELIBERADA}

Originada nos tribunais ingleses, principalmente no caso Regina v. Sleep, a teoria em comento, denominada willful blindness, deliberate ignnorance, conscious avoidance doctrine ou ignorancia deliberada, relaciona-se a casos em que o agente fingiria não perceber determinada situação de ilicitude para, a partir daí, alcançar a vantagem pretendida.

De acordo com Bernardo Feijoo Sánchez (2005, tradução nossa), a doutrina da cegueira deliberada, em essência, trata o sujeito que provoca deliberada e intencionalmente sua própria ignorância, a fim de "facilitar ou tornar mais cômoda sua decisão moral", àquele que realiza a conduta delitiva de forma intencionada ou deliberada. Por sua vez, Isidoro Blanco Cordero (2012, p. 692, tradução nossa), tratando do tema, explica que, por força da willful blindness doctrine, se uma pessoa realiza um plano de ação sem nenhuma investigação e opta por ignorar a realidade, "o direito lhe imputa o conhecimento do que poderia haver conhecido."

Do ponto de vista jurídico, para que a cegueira deliberada possua relevância são necessários alguns requisitos (SYDOW, 2017, p. 54), dentre os quais: a) que se trate de um agir para não receber uma informação relevante ou um não agir para esclarecer uma informação relevante; b) que essa informação relevante componha um tipo penal em um de seus aspectos subjetivos (tipicidade ou relação de causalidade); c) que essa conduta gere uma ideia de reprovação obtida caso o agente seja descoberto; e d) que essa informação esteja disponível, pois, como atenta Ragués i Vallès (2007, p. 157, tradução nossa), "só se pode dizer que decidiu ignorar deliberadamente o sujeito que está em condições de conhecer."

O autor acrescenta, ainda, como requisito para um conceito jurídico-penal do instituto, o dever de obter a informação ignorada - exigência esta, segundo ele, "própria de qualquer modelo de imputação subjetiva em que vigora o princípio da culpabilidade". Só se pode ter responsabilidade pela falta de conhecimento, assim, caso haja um dever de conhecer aquilo que se ignorou, nada obstante o jurista se contente com a simples "inobservância do dever geral de atentar aos riscos associados à realização de comportamentos potencialmente lesivos a interesses alheios”. (RAGUÉS I VALLÈS, 2007, p. 157, tradução nossa). 
De acordo com a doutrina, a teoria da cegueira deliberada tem por finalidade resolver uma específica situação lacunosa criada a partir da premissa de que o indivíduo "escolhe o grau de conhecimento que deseja ter e por tal decisão responde" (SYDOW, 2017, p. 22). Conforme elucida Spencer Toth Sydow (2017, p. 19), a lacuna existiria porque a teoria do delito trata da tipicidade como um conceito positivo, deixando de abarcar as situações em que o sujeito de um delito alega desconhecimento de fatos por desídia em investigá-los ou pela criação de estratégias para jamais alcançar essa consciência.

O autor explica que a teoria trabalha com a problemática de duas possíveis situações:

(a) a primeira, em que um agente se coloca em situação de cegueira em relação a um ou mais elementos do tipo, em momento anterior à prática da conduta e, quando a conduta ocorre no futuro, encontra-se (ou assim afirma) desprovido de conhecimento acerca de tal (tais) elemento - denominada "cegueira deliberada em sentido estrito"; e (b) a segunda, em que o agente não se coloca em situação de ignorância em relação a um ou mais elementos do tipo mas, suspeitando da existência de tal elemento, deixa de diligenciar no sentido de afastar sua dúvida ou corrigir seu desvio evitando, assim, conhecimento e eventualmente responsabilidade - denominada "ignorância deliberada". (SYDOW, 2017, p. 22).

Levando em consideração que o princípio da legalidade exige a presença e representação, pelo autor, de todos os elementos integradores da conduta prevista, então o não conhecimento - ainda que em decorrência de uma auto colocação em estado de não consciência - esvaziaria o conteúdo típico do injusto em certas situações. Isso porque a existência de elemento subjetivo, dentro da concepção finalista, é elementar para a configuração do tipo, especialmente quando este (a exemplo do que ocorre com o delito de lavagem de capitais) não previu punição para a conduta culposa.

Ademais, para além do comentado artigo 18, inciso I, do Código Penal, lembre-se que o artigo 20 do mesmo estatuto repressivo apresenta que o erro - a falsa percepção da realidade - sobre elemento constitutivo do tipo penal exclui o dolo, sendo então possível concluir que, do mesmo modo, a ignorância - o total desconhecimento da realidade - também o excluiria.

Ragués i Vallès (2007, p. 21, tradução nossa) explica que, diferentemente do que ocorre nos países de tradição common law, no sistema jurídico espanhol e em ordenamentos próximos o dolo eventual permite resolver satisfatoriamente a maioria dos casos em que "uma pessoa realiza um comportamento objetivamente típico havendo renunciado voluntariamente conhecer com exatidão alguns dos aspectos penalmente relevantes de sua conduta.”

Com efeito, em várias decisões proferidas desde o ano de 2000 o Tribunal Supremo Espanhol se declarou partidário da inclusão, dentro do conceito de dolo, das situações de ignorância deliberada. É dizer: quando o sujeito ativo de um delito tiver renunciado 
voluntariamente a adquirir os conhecimentos que, possuindo no momento de realizar o tipo, teriam tornado a imputação dolosa, então sua conduta seria também equiparada à ação de natureza dolosa. O primeiro julgado daquela Corte que cita a teoria esclarece que se trata da

\begin{abstract}
situação em que o sujeito não quer saber aquilo que pode e deve conhecer, ou seja, um estado de ausência de representação em relação a um determinado elemento do tipo em que devem concorrer duas características, a capacidade do sujeito em abandonar tal situação caso queira e o dever de procurar tais conhecimentos. Há, ainda, um terceiro requisito: o fato de que o sujeito se beneficia da situação de ignorância por ele mesmo buscada (sem que a Sala Segunda especifique se tal vantagem deve ser econômica ou de outra ordem). (RAGUÉS I VALLÈS, 2007, p. 25 , tradução nossa).
\end{abstract}

No ordenamento jurídico estadunidense, a partir da segunda metade do século XX a willful blindness doctrine foi aplicada em diversas ocasiões por tribunais inferiores, destacandose, nos anos de 1970, os casos de tráfico de drogas. Nos precedentes Turner v. United States e United States v. Jewell, de 1976, restou consolidado o entendimento de que quem é consciente da "alta probabilidade" da existência de um crime e não faz o necessário para confirmar tal existência merece o mesmo tratamento daquele que possui a plena certeza sobre o delito. (KLEIN, 2012, p. 4).

As soluções apresentadas acima, entretanto, estão longe de alcançar unanimidade na doutrina ou jurisprudência. Além de já ter sido utilizada para conduzir a condenações tanto dolosas como culposas, a teoria da cegueira deliberada chegou a ser tratada, por vezes, como uma nova forma de imputação subjetiva, diversa do dolo e da imprudência, e seu raio de aplicação, como visto, foi amplamente estendido.

Várias são as dificuldades elencadas pela doutrina para a aplicação do instituto. Sem a pretensão de esgotar todas as críticas nos limites do presente trabalho, optaremos por apresentar somente as considerações que de forma mais direta interessem ao estudo aqui proposto.

Luis Greco (2013, p. 74-75) destaca certos riscos na lógica da teoria, apontando que se levarmos em consideração a conduta prévia do agente como reprovável nos moldes dolosos propostos, o desconhecimento quanto a uma situação de fato o coloca numa situação de reprovabilidade excessivamente ampla, pois que sua conduta potencialmente poderia gerar o cometimento de diversos delitos. Assim, no exemplo do indivíduo que desidiosamente deixasse de verificar os compartimentos do veículo que transportaria, estaria ele passível de imputação de responsabilidade por diversos crimes, de tráfico de drogas a tráfico de armas ou receptação.

Spencer Sydow (2017, p. 146-147) considera que, se a figura da cegueira deliberada é composta por dois atos - um ato inicial, consistente na conduta geradora da situação de desconhecimento e um ato posterior, consistente na consequência não desejada e que ocorre 
como resultado do desconhecimento anterior -, diversos problemas podem decorrer quando haja um elevado lapso temporal entre a conduta de obscurecimento e a descoberta do resultado lesivo, a exemplo do perdimento de dados. Outrossim, o autor destaca que a utilização de estratégias preventivas é absolutamente comum no âmbito empresarial, de modo que

\footnotetext{
Uma forte insegurança jurídica poderia se instalar na sociedade e suas relações posto que se imporia a empresas e indivíduos a obrigação de acompanhar todas as consequências advindas de suas estratégias preventivas e todos os indivíduos que por elas fossem afetados.

Interessante também destacar que o ato secundário (consequência indesejada) não necessariamente terá sido praticado pela pessoa responsável pelo obscurecimento, o que torna ainda mais difícil o controle da responsabilidade jurídica pelo fato, colocando muitas vezes na mão de terceiros situações que podem gerar reprovabilidade a um indivíduo ou pessoa. (SYDOW, 2017, p. 149).
}

Não escapa a uma série de questionamentos, ainda, o critério da "alta probabilidade" muito adotado pelo sistema norte-americano para a aceitação da figura da willful blindness especialmente após o surgimento, em 1962, do Código Penal Modelo (Model Penal Code), que dispôs que o requisito do conhecimento da existência de um fato particular deve ser considerado satisfeito "se a pessoa está ciente da alta probabilidade de sua existência, exceto se a pessoa verdadeiramente acredita que este não existe" (Seção 2.02(7)).

Em primeiro lugar, seria necessário um parâmetro numérico para se auferir normativamente o que significa a expressão, o qual, não existindo, resulta em um elevado grau de liberdade de interpretação e de aplicação aos seus destinatários, com prejuízo à segurança jurídica. Ademais, parece-nos bastante pertinente a observação feita, mais uma vez, por Spencer Sydow (2017, p. 160-161), para quem a análise da "alta probabilidade", ainda que feita ex post facto, deve considerar o momento ex ante facto, não sendo possível partir do pressuposto de que todos os elementos agora conhecidos também o eram no momento da conduta.

A situação seria, então, não de probabilidade, mas de previsibilidade, vez que

No máximo, um cidadão conseguiria exercitar uma projeção de resultados possíveis
de sua atitude. Mas tal instituto é o da previsibilidade. Entregar ao cidadão o ônus de
identificar todas as variáveis possíveis e ponderar quantas delas o colocariam em
situação de ilícito é, em verdade, irreal. É apanhar o conhecimento que o magistrado
tem post facto e presumi-lo ante facto. (SYDOW, 2012, p. 161).

A maior crítica, contudo, especialmente no que tange à aplicação da teoria no ordenamento brasileiro, está associada à aparente e já comentada ofensa ao princípio da legalidade. Isso porque, consoante pontuado anteriormente, a definição de dolo no Código Penal pátrio pode ser comprovada pela leitura conjunta dos artigos 18, inciso I, e 20, caput, do referido diploma, que exigem - seja para o dolo direito, seja para o dolo eventual - o efetivo e atual conhecimento dos elementos integrantes do tipo. 
O "conhecimento potencial dos elementos do tipo objetivo" não configura o dolo eventual, portanto, ao menos da forma como foi prevista a figura em nossa legislação (SILVA; LAUFER, 2015). Sobre o tema da cegueira deliberada e sua relação com a legalidade, finalizamos, por ora, com a lição de Ragués i Vallès (2007, p. 196), ao dizer que

\begin{abstract}
nos sistemas jurídicos em que se optou por definir legalmente o dolo exigindo, de maneira direta ou indireta, conhecimento de determinados elementos típicos, afirmar que é conhecedor quem atua em um estado de ignorância a respeito de tais elementos parece impossível sem forçar a letra de lei para além do desejável: tratar-se-ia de uma autêntica 'contradictio in terminis' dificilmente aceitável por um princípio da legalidade que queira conservar uma mínima vigência.
\end{abstract}

Por mais que se defenda, como Greco (2009, p. 886), que os limites trazidos pelo legislador não significam o fim, e sim o início da filosofia, que passa a ter a função de investigar se o texto legislativo está arrimado "apenas na autoritas do poder de quem decide, ou também na veritas das razões que a justificam", é certo que eles estabelecem balizas, sobretudo quando se trata de restrições a direitos fundamentais e ampliações da figura típica. Por isso que a doutrina da cegueira deliberada é construída à margem do ordenamento jurídico vigente, embora muito comum seja equipará-la ao dolo eventual.

\title{
3 A APLICAÇÃO DA TEORIA DA CEGUEIRA DELIBERADA AO CRIME DE LAVAGEM DE CAPITAIS NO DIREITO PENAL BRASILEIRO
}

Nas últimas décadas do século XX a teoria da cegueira deliberada passou a ser amplamente aplicada a outros delitos, ganhando destaque quanto a sua utilização com a finalidade de fundamentar a responsabilidade das pessoas jurídicas nos casos em que algum de seus dirigentes tenha se colocado, deliberadamente, em uma situação de desconhecimento.

Conforme faz questão de ressaltar a doutrina, importante não confundir o instituto com situações de legítimo desconhecimento das circunstâncias fáticas ou objetivas advindas do instituto da ignorância verdadeira (SYDOW, 2017, p. 72). Igualmente diverso é o caso do indivíduo que, por exemplo, busca opinião legal para se resguardar de responsabilidade penal eventual e mesmo assim comete o injusto - nessa hipótese, há consciência de uma possível antijuridicidade, uma dúvida sobre a reprovabilidade social da conduta inteiramente compreendida em seus elementos (LEITE, 2013).

Isso porque, "na cegueira deliberada em sentido amplo, a conduta em si - em algum elemento do tipo que a compõe - é desconhecida e o modo pelo qual surge tal desconhecimento é ou por desídia ou por uma composição artificial da realidade fática”. (SYDOW, 2017, p. 72). 
Por interpretação analógica e inspiração nos precedentes estrangeiros, a literatura penal e a jurisprudência brasileiras tem admitido a aplicação da teoria e igualado este grau de culpabilidade ao dolo eventual, especialmente nos crimes de lavagem de dinheiro. Nesta hipótese, a situação estaria configurada quando “o agente, apesar de ter condições de aprofundar seu conhecimento sobre os fatos, ou seja, sobre a origem ou natureza dos bens, direitos ou valores envolvidos, escolhe permanecer alheio a esse conhecimento". (MORO, 2007, p. 100).

Ocorre que, como visto, inúmeras são as opiniões contrárias ao cabimento do dolo eventual no delito de lavagem de capitais, mormente quando, após a exclusão do rol de crimes antecedentes pela Lei n.12.683/2012, qualquer infração penal geradora de ativos pode figurar como precedente ao mascaramento. A rigor, dada a fungibilidade do objeto do crime, sempre seria possível duvidar da procedência de determinado bem ou capital, situação que imporia aos profissionais que atuam nos setores sensíveis da economia incessante investigação sobre toda e qualquer operação que efetivem.

Mas não é só. Ainda que superada a questão anterior, como parece ser a tendência jurisprudencial desde as alterações promovidas na lei em 2012, se o requisito do conhecimento do autor acerca do elemento subjetivo do tipo puder ser satisfeito pela prova de mera suspeita da existência de circunstâncias, então o sujeito ficaria induzido a superar a situação de ignorância em situações reais, posto que aos tribunais bastaria a demonstração de que existia algum grau de suspeita possível e uma probabilidade alta de que essa suspeita mal investigada poderia configurar uma circunstância relevante à causação de um delito.

Essa tática, como alerta Assaf Hamdami (2007), geraria impactos úteis à lógica do ônus da prova da acusação. Na mesma linha, analisando algumas decisões proferidas pelo Supremo Tribunal Espanhol, Ragués i Vallès (2007, p. 59) anota que o recurso à teoria tem sido especialmente proveitosa em dois contextos: em alguns casos, porque em sua fundamentação jurídica a corte não se esforçou em individualizar e mencionar os correspondentes indícios de conhecimento que poderia ter encontrado nos fatos provados; em outros, porque tais indícios simplesmente não existiam e, portanto, de acordo com o método de inferência tradicional, não cabia atribuir ao acusado o conhecimento necessário a uma condenação por crime doloso decisão que, por outro lado, foi possível alcançar com base no novo instituto.

Para Ana Luiza Klein (2012, p. 74), o caso brasileiro é diferente do espanhol e do americano principalmente porque, aqui, há definição legal dos elementos cognitivos (artigo 20, caput, do CP) e volitivos (artigo 18, I, do CP) do dolo. No caso espanhol, o dolo é fruto de uma tradição doutrinária e jurisprudencial, sendo possível utilizar o conceito anglo-saxão de 
conhecimento em potencial da cegueira deliberada. Assim, conclui a autora dizendo que representa uma violação ao princípio da legalidade igualar o conhecimento à probabilidade de conhecimento dos elementos normativos e descritivos do tipo objetivo, pois isto significa uma inevitável ampliação do conceito de dolo, com a criação de categorias praeter legem.

Para além da inexistência de estudos mais aprofundados no Brasil, especialmente no que tange às diferenças entre a legislação pátria e as demais nações que acolheram a teoria da cegueira deliberada, Spender Sydow (2017, p. 229) menciona o problema alusivo à possibilidade de utilização do instituto como forma de esquivar-se de uma aprofundada fundamentação quanto ao elemento subjetivo do crime. De acordo com o autor, ao afirmar que o agente tinha "intenção de não querer saber", deve o julgador demonstrar concretamente tal circunstância, sob pena de tornar a decisão não adequadamente fundamentada e, no que se refere à aplicação da cegueira deliberada, arbitrária.

Com efeito, é certo que ignorar riscos elevados e evidentes pode, conforme as circunstâncias, representar um juízo de desvalor capaz de ensejar uma imputação dolosa. Todavia, como sustenta Ragués i Vallès (2012, p. 09), para que uma proposta teórica consiga sustentar a possibilidade de tratamento como crime doloso é preciso que o déficit de representação se veja compensado por uma certa motivação especialmente desvaliosa, que justifique um tratamento mais severo. Considera discutível, contudo, naqueles casos em que a razão para a cegueira não seja a falta de interesse em conhecer, ou mesmo um descuido grave diante de um risco muito elevado, que o fato seja uma expressão daquilo que legitima a imposição de uma pena a título de dolo.

Robson Galvão e Christian Laufer (2015) argumentam que, no Brasil, a abordagem da teoria tem se dado com clara inversão na ordem de importância do que efetivamente deve ser analisado. Sendo evidente que, em qualquer situação, sempre será possível ao agente conhecer mais a fundo as circunstâncias do caso concreto, o foco do estudo não deve ser dirigido àquilo que o indivíduo não sabe, mas ao que está devidamente representado pelo autor ao decidir prosseguir agindo. Assim, o problema não reside em não se aprofundar no conhecimento, mas no grau de conhecimento presente no momento da prática da conduta típica - existentes provas ou sérios indícios de lavagem, poderá haver dolo eventual, independentemente de o agente ir além na investigação. Contudo, na ausência de elementos hábeis capazes de suscitar uma fundada consciência ou representação sobre os elementos do tipo, não há dolo, porquanto o conhecimento exigível para a sua configuração deve ser atual, e não potencial. 
Levando em consideração todas as dificuldades apresentadas, alguns autores buscam enumerar requisitos claros e seguros para que, no caso concreto, seja possível igualar a cegueira deliberada ao dolo eventual, conforme a previsão contida no Código Penal brasileiro. Especificamente para a lavagem de dinheiro, Pierpaolo Bottini (2013), após criticar a aceitação do dolo eventual como elemento subjetivo do crime, sugere algumas cautelas na aplicação do instituto, aduzindo ser necessária a) a criação consciente e voluntária de mecanismos que obstem o conhecimento de sinais sobre a procedência criminosa dos bens e/ou valores; e b) a representação, pelo agente, da possibilidade da evitação recair sobre atos de mascaramento. ${ }^{12}$

No mesmo viés, Beck (2011, p. 64) pondera que há problemas na cegueira deliberada cuja solução demandaria uma reestruturação do sistema de imputação, "que reconheça como genericamente puníveis certas configurações subjetivas (como o dolo eventual e algumas modalidades de ignorância deliberada), mas com consequências punitivas menos severas que em outras formas de dolo". No entanto, as questões sobre a lavagem de dinheiro e o elemento subjetivo deveriam ser resolvidos a partir dos paradigmas normativos do Código Penal, a partir das concepções de dolo eventual, sem a necessidade de recorrer à teoria em estudo.

A admissão do dolo eventual para todas as condutas delitivas tipificadas na Lei n. 9.613/1998, indiscriminadamente, já não parece muito recomendável e enfrenta fortes críticas doutrinárias. Nessa linha, seu reconhecimento na forma da cegueira deliberada parece ainda menos adequado a um sistema penal pautado pelos princípios da legalidade e da culpabilidade, especialmente quando os impactos acerca da importação dessa teoria ainda carecem de estudos e debates mais aprofundados.

Ademais, recorrer-se a um instituto oriundo de doutrina estrangeira, sem um equivalente normativo codificado, apenas para estabelecer um critério mais elástico de imputação subjetiva, em nome da "eficiência" do sistema, não parece coadunar-se com um sistema de garantias próprios do Estado Democrático de Direito.

\section{CONCLUSÕES}

A teoria da cegueira deliberada surgiu no intuito de suprir pretensas lacunas existentes no estudo do elemento subjetivo do tipo, o qual foi construído levando em consideração

\footnotetext{
${ }^{12} \mathrm{O}$ autor chega a sugerir que, talvez, "melhor que equiparar o dolo eventual à cegueira deliberada, seja a criação legislativa de novas modalidades de imputação subjetiva, para além do dolo e da culpa, com patamares distintos de punição para cada categoria, evitando-se o alargamento e a imprecisão dos institutos” (BOTTINI, 2013).
} 
institutos positivos como intenção e consciência, deixando de abarcar, noutro giro, as hipóteses em que o agente alega ignorância de circunstâncias objetivas por desídia de investigá-los ou pela criação de estratégias para nunca adquirir tal conhecimento.

De acordo com diversos autores, não cabe admitir que situações de desconhecimento sejam tratadas como casos de dolo, notadamente porque este requer sempre a representação de todas as circunstâncias objetivas que integram o delito. No Brasil, pode-se afirmar que a questão é ainda mais tormentosa, haja vista que o Código Penal apresenta uma definição legal de dolo nitidamente incompatível com as hipóteses comumente tratadas em outros países como casos de cegueira deliberada.

Especificamente quanto ao delito de lavagem de capitais, o primeiro óbice à aplicação do instituto recai sobre a acirrada discussão quanto à aceitação do dolo eventual em face das condutas tipificadas na Lei n. 9.613/1998. Nada obstante, tem sido frequente a menção à teoria em comento para alcançar o elemento subjetivo do crime de mascaramento, justamente na modalidade do dolo eventual.

É imprescindível, sob pena de grave violação aos princípios constitucionais da legalidade e da culpabilidade, que sejam adotadas limitações ao uso da willful blindness no ordenamento pátrio, mormente para evitar que o manejo da teoria sirva como escudo ao dever do magistrado de apontar, de forma fundamentada e com base em elementos concretos, os indícios de conhecimento do agente quanto à procedência infracional dos bens, direitos e valores e a assunção do risco de produzir o resultado lesivo.

\section{REFERÊNCIAS}

BADARÓ, Gustavo Henrique; BOTTINI, Pierpaolo Cruz. Lavagem de dinheiro: aspectos penais e processuais penais: comentários à Lei 9.613/1998, com alterações da Lei 12.683/2012. São Paulo: Revista dos Tribunais, 2012.

BARROS, Marco Antonio de. Lavagem de capitais e obrigações civis correlatas: com comentários, artigo por artigo, à Lei 9.613/1998. 3. ed. rev. atual. e ampl. São Paulo: Revista dos Tribunais, 2012.

BECK, Francis. A doutrina da cegueira deliberada e sua (in) aplicabilidade ao crime de lavagem de dinheiro. Revista de Estudos Criminais, Sapucaia do Sul, n. 41, p. 45-68, set. 2011. 
BOTTINI, Pierpaolo. A cegueira deliberada no julgamento da Ação Penal 470. Consultor Jurídico, 30 jul. 2013. Disponível em: <http://www.conjur.com.br/ 2013-jul-30/direitodefesa-cegueira-deliberada-julgamento-acao-penal-470>. Acesso em: 5 abr. 2017.

BRANDÃO, Nuno. Branqueamento de capitais: o sistema comunitário de prevenção. Coimbra: Coimbra Editora, 2002.

BRASIL. Decreto-lei no 2.848, de 7 de dezembro de 1940. Código Penal. Diário Oficial [da] República dos Estados Unidos do Brasil, Rio de Janeiro, 31 dez. 1940. Disponível em: <http://www.planalto.gov.br/ccivil_03/decreto-lei/del2848.htm>. Acesso em: 3 abr. 2017.

Poder Legislativo. Lei n. 9.613, de 3 de março de 1998. Disponível em: <http://www.planalto.gov.br/ccivil_03/leis/19613.htm〉. Acesso em: 2 abr. 2017.

. Presidência da República. Divisão de Atos Internacionais. Decreto n. 154, de 26 de junho de 1991. Promulga a Convenção das Nações Unidas contra o Tráfico Ilícito de Entorpecentes e Substâncias Psicotrópicas. Disponível em:<http://www.planalto.gov.br/ ccivil_03/decreto/1990-1994/D0154.htm>. Acesso em: 2 abr. 2017.

Presidência da República. Divisão de Atos Internacionais. Decreto n. 5.687, de 31 de janeiro de 2006. Promulga a Convenção das Nações Unidas contra o Crime Organizado Transnacional. Disponível em: <http://www.planalto.gov.br/ccivil_03/_ato20042006/2004/decreto/d5015.htm>. Acesso em: 3 abr. 2017.

Presidência da República. Divisão de Atos Internacionais. Decreto n. 5.015, de 12 de março de 2004. Promulga a Convenção das Nações Unidas contra o Crime Organizado Transnacional. Disponível em: <http://www.planalto.gov.br/ccivil_03/_ato20042006/2004/decreto/d5015.htm>. Acesso em: 3 abr. 2017.

CALLEGARI, André Luís. Lavagem de dinheiro. São Paulo: Manole, 2004.

CAPARRÓS, Eduardo Fabián. El delito de blanqueo de capitales. Madrid: Colex, 1998. In: PITOMBO, Antônio Sérgio A. de Moraes. Lavagem de dinheiro: a tipicidade do crime antecedente. São Paulo: Editora Revista dos Tribunais, 2003.

CORDERO, Isidoro Blanco. El delito de blanqueo de capitales. 3. ed. Navarra: Editorial Aranzadi S.A., 2012.

DE CARLI, Carla Veríssimo. O controle penal da lavagem de dinheiro - Dos crimes: aspectos objetivos. In: DE CARLI, Lavagem de dinheiro: prevenção e controle penal. Porto Alegre: Verbo Jurídico, 2011.

FEIJÓO SÁNCHEZ, Bernardo. La distinción entre dolo e imprudencia em los delitos de resultado lesivo. Sobre la normativización del dolo. Cuadernos de Política Criminal, n. 65, Madrid, Edersa, 1998, p. 269-364.

FILIPPETTO, Rogério. Lavagem de dinheiro: crime econômico da pós-modernidade. Rio de Janeiro: Lumen Juris, 2011. 
GEHR, Amanda. A aplicação da teoria da cegueira deliberada no direito penal brasileiro. Curitiba: 2012. Disponível em: <http://acervodigital.ufpr.br/bitstream/handle/1884/31107/ AMANDA\%20GEHR.pdf?se>. Acesso em: 3 abr. 2017

GRECO, Luis. Comentario ao artículo de Ramón Ragués. Discusiones XIII. Ignorancia deliberada y Derecho Penal, Buenos Aires, dez. 2013. Disponível em:

$<$ http://www.academia.edu/22655140/Discusiones_XIII_Ignorancia_deliberada_y_derecho_p enal>. Acesso em: 3 abr. 2017.

Dolo sem vontade. In: DIAS, Augusto Silva e outros [coords.]. Líber Amicorum de José de Sousa Brito em comemoração do $70^{\circ}$ Aniversário. Coimbra: Almedina, 2009, p. 885903.

HAMDAMI, Assaf. Mens rea and the cost of ignorance. 93 Virginia Law Review, 415, 2007. Disponível em: <https://papers.ssrn.com/sol3/papers.cfm?abstract_id=892700>. Acesso em: 4 abr. 2017.

KLEIN, Ana Luiza. A doutrina da cegueira deliberada aplicada ao delito de lavagem de capitais no direito penal brasileiro. Porto Alegre: Editora Universitária da PUCSRS, 2012. Disponível em: <http://ebooks.pucrs.br/edipucrs/anais/cienciascriminais/III/4.pdf>. Acesso em: 4 abr. 2017.

LEITE, Alaor. Dúvida e erro sobre a proibição no direito penal. São Paulo: Atlas, 2013.

MAIA, Rodolfo Tigre. Lavagem de dinheiro (lavagem de ativos provenientes de crime): anotações às disposições criminais da Lei n. 9.613/98. 1. ed. São Paulo: Malheiros Editores, 1999.

MELLO, Sebástian Borges de Albuquerque. Microssistemas jurídico-penais e a lavagem de dinheiro: Aspectos da Lei 9.613/98. Revista Jurídica dos Formandos em Direito da UFBA, Salvador, ano 4, v. 4., UFBA, 1999

MINISTÉRIO DA JUSTIÇA, Exposição de Motivos n. 692/MJ, de 18 de dezembro de 1996, publicada no Diário do Senado Federal de 25 de novembro de 1997. Disponível em: <http://www.coaf.fazenda.gov.br/menu/legislacao-e-normas/legislacao1/Exposicao\%20de\%20Motivos\%20 Lei\%209613.pdf/view>. Acesso em: 2 abr. 2017.

MORO, Sergio Fernando. Sobre o elemento subjetivo no crime de lavagem. In: BALTAZAR JUNIOR, José Paulo; MORO, Sergio Fernando (org.). Lavagem de dinheiro: comentários à lei pelos juízes das varas especializadas em homenagem ao Ministro Gilson Dipp. Porto Alegre: Livraria do Advogado, 2007.

PASSOS, Thaís Bandeira Oliveira. Lavagem de capitais: (dis)funções político-criminais no seu combate. Salvador: JusPodivm, 2011.

PORCIÚNCULA, José Carlos. Lo "objetivo" y lo "subjetivo" em el tipo penal. Hacia la "exteriorización de lo interno." $1^{\mathrm{a}}$ ed. Barcelona: Atelier, 2014. 
PRADO, Luiz Regis. Delito de lavagem de capitais: um estudo introdutório. In: PRADO, Luiz Regis; DOTTI, René Ariel (org.). Direito penal da administração pública - Coleção doutrinas essenciais: direito penal econômico e da empresa; v. 4. São Paulo: Revista dos Tribunais, 2011.

PRADO, Rodrigo Leite. O controle penal da lavagem de dinheiro - Dos crimes: aspectos subjetivos. In: DE CARLI (org.). Lavagem de dinheiro: prevenção e controle penal. Porto Alegre: Verbo Jurídico, 2011.

RAGUÉS I VALLÉS, Ramón. De nuevo, el dolo eventual: un enfoque revolucionario para un tema clásico. Recensión a Gabriel Pérez Barberá, El dolo eventual. Hacia el abandono de la idea de dolo como estado mental. InDret. Revista para el Análisis del Derecho, Barcelona, n. 3, jul. 2012. Disponível em: <http://www.indret.com/pdf/899.pdf>. Acesso em: 10 maio 2017. 2007.

La ignorancia deliberada em Derecho penal. Barcelona: Atelier Libros Juridicos,

SANCHEZ, Bernardo Feijoo. La teoría de la ignorancia deliberada em derecho penal: uma peligrosa doctrina jurisprudencial. InDret. Revista para el Análisis del Derecho, Barcelona, n. 3, jul. 2005.

SILVA, Robson A. Galvão; LAUFER, Christian. A cegueira deliberada na lava-jato. Empório do Direito, 15 nov. 2015. Disponível em: <http://emporiododireito.com.br/a-cegueiradeliberada-na-lava-jato-por-robson-a-galvao-da-silva-e-christian-laufer/>. Acesso em: 4 abr. 2017.

SYDOW, Spencer Toth. A teoria da cegueira deliberada. Belo Horizonte: Editora D'Plácido, 2017. 